\title{
Professional identity and methods of its study
}

\author{
Nailya Khakimoma $^{1 *}$, Rezida Khusnutdinova $^{2}$, Rustem Galiev ${ }^{3}$, Lenar Galiev $^{4}$, Svetlana \\ Chirkova $^{5}$, and Tatyana Garnysheva ${ }^{2}$ \\ ${ }^{1}$ Department of Pedagogy, Naberezhnye Chelny State Pedagogical University, Naberezhnye Chelny, \\ Russia \\ ${ }^{2}$ Department of Psychological, Pedagogical and Special Defectological Education, Naberezhnye \\ Chelny State Pedagogical University, Naberezhnye Chelny, Russia \\ ${ }^{3}$ Scientific Research Department, Naberezhnye Chelny State Pedagogical University, Naberezhnye \\ Chelny, Russia \\ ${ }^{4}$ Institute of Continuing Professional Education, Naberezhnye Chelny State Pedagogical University, \\ Naberezhnye Chelny, Russia \\ ${ }^{5}$ Department of History and Methods of Its Teaching, Naberezhnye Chelny State Pedagogical \\ University, Naberezhnye Chelny, Russia
}

\begin{abstract}
The article is devoted to the phenomenon of "professional identity" as a psychological-pedagogical category. The article deals with the content of the concept of "professional identity" in the works of domestic and foreign authors; data are given in accordance with which, in the works of foreign authors, professional identity is associated with personal self-improvement and professional development; is considered as an element of personal identity. The formation of professional identity is influenced by the social aspects of life and the factors of becoming a professional. The authors emphasize that domestic scientists designate a professional identity: as a product of professional and personal development; as an integral part of personal identity. Therefore, the work pays special attention to the psychobiographical approach to the study of professionalization.
\end{abstract}

\section{Introduction}

In modern Russian psychology the basis of the understanding of the human process of professionalization is subject approach, which allows to consider the professional formation of an individual, including a teacher, as a way of self-development throughout life, a form of formation of his subjectivity. In our opinion, the involvement of the subjective approach allows us to single out the main mechanism of human development in the profession: the construction of one's own activity and oneself as a professional. We consider Iconcentration as a psychological support for the functioning of this mechanism. The meeting of a person and a profession is not a one-time event, and that professional training and special forms of increasing motivation are very important to achieve their compliance [1], [2].

\footnotetext{
* Corresponding author: 340268@mail.ru
} 
In numerous theoretical and experimental developments, the professional development of a person is a rather long and complex process, comparable to life (T.V. Kudryavtsev) [3].

A special role in the theory of T.V. Kudryavtsev was recognized for the crises of development that arise during the transition from one component of activity, for example, motivational-need at the stage of entering a new professional team, to another, operational and technological.

The crisis in professional self-determination and the formation of professional identity can be viewed as a kind of "chance" for a person to become better, and for a professional to move to the next stage of his development. As researchers of professional development (E.F. Zeer, E.A. Klimov) note, it is the change or restructuring of the hierarchy of life and professional values that underlie professional development [4], [5].

Traditionally, in studies of professional identity, its psychobiographical aspect remains aside. D.N. Zavalishina notes that with the traditional approach, taking into account the attitude towards a personal future in this profession, the individual handwriting of professionalization, remain aside. Therefore, in our work, special attention is paid to the psychobiographical approach to the study of professionalization [6].

In Russian psychology, the problems associated with the study of a person in time, with the study of his life path began to be actively developed in the late 70s of the XX century. The relationship between the concepts of "future time perspective", "life perspective" and "subjective picture of life" is analyzed. All of these concepts are associated with a psychobiographical approach to the study of professional identity, professional vocation, or disappointment in the chosen profession [7], [8], [9].

Sociological studies of a life perspective have shown that a person should know what prospects a profession opens up in areas that are significant for him. Ideally, each profession should be presented from the point of view of a person's life perspective, in which both possible achievements and possible difficulties in the implementation of certain value orientations and life orientations would find place [10], [11], [12], [13], [14], 15].

\section{Materials and methods}

It is noted that the scientific solution to assess the productivity of life was delivered in a psychobiographical approach. It was associated with the search for appropriate criteria, and the difficulties encountered by the researcher are mainly due to the complexity of the very object of human life. First, it is necessary to take into account the many spheres of life, in each of which productivity can be characterized by different, directly incomparable indicators. Secondly, the productivity of life can be assessed both from the point of view of the benefits that a person objectively brings to society and the people around him, and from the standpoint of his internal self-esteem of life.

The concept of "life productivity" is used to characterize a certain set of life successes and achievements of a person. However, until now, sufficiently strict criteria have not been developed, on the basis of which an integrative measurement of the productivity of a person's life as a whole and its individual stages would become real.

According to E. I. Golovakha, there is one very simple criterion that allows you to avoid complex problems associated with the analysis of substantive aspects of a person's life path [16]. In our research, we operate with a substantive criterion - the saturation of life, which characterizes a person's life path in terms of activity and its results.

A person's life can be more or less saturated with various types of activities, actions and deeds, successes and failures, i.e. deeds and results. But life is also about feelings, experiences, plans, hopes, dreams and disappointments. This implies the need to separate and compare objective and subjective indicators of life productivity. The objective duration of life and its individual periods can be measured by the total or relative saturation of the 
forms and products of human activity. The main question here is specific indicators of saturation, units of its measurement.

A broader approach to the problem is contained in the research of psychologists who develop biographical methods for studying the life path of a person. For the first time, a comprehensive biographical research covering all age stages and spheres of human life was carried out by the research team of the Vienna Institute of Psychology under the leadership of S. Buhler in the middle of the 20th century [17]. The study used survey methods, clinical interviews, analysis of documents (autobiographies, diaries, letters, etc.).

The data were systematized into three main groups:

1) external life events-spheres of activity and forms of personality behavior;

2) internal reactions to events- a person's relationship to life;

3) achievements, successes of a person in professional activity, for personal purposes, in influencing other people- objective results of the life path.

\section{Results and discussion}

The total saturation of various age periods was determined using the number of so-called measurements - the spheres of activity of the individual, which he was involved in at a given age. 97 dimensions were identified: work, family, friendship, sports, travel, study, hobbies, etc. Any dimension can be represented graphically by the years of its beginning and end on a line that conventionally denotes a person's life. The more measurements there are at a certain age, the more saturated a person's life at this age. According to biographical research, the most intense is the period of maturity, which is a kind of culmination of life (the average age of its beginning is 28.6 years, the end is 48.5 years). This period accounts for the maximum number of measurements, although in the subsequent period (48.5-63.8 years) the number of measurements does not decrease very significantly, only in the last period of life there is a sharp decrease in the number of measurements. The culmination period is preceded by two others: the first - from birth to 17 years, the second from 17 to 28.6 years. During these periods, positive dimensions prevail - life gains, and the last two are characterized by an increase in the number of negative dimensions - losses.

Using the "measurements" method, the age dynamics of the saturation of life can be represented in the form of a graph characterizing the rise in childhood and adolescence, a plateau in maturity and a decline in old age. This picture is confirmed by studying the objective results of the life path and the subjective attitude of a person to his own life in the corresponding age periods.

The possibilities of the "measurement" method in the study of life productivity are very limited. It gives an idea of the saturation of life only with various spheres of activity, which can differ significantly in the levels of personality activity, which must be taken into account when measuring the total and relative saturation of life and its individual periods. In this regard, an important methodological question arises about the units for measuring the saturation and, accordingly, the productivity of life. These units must be universal, i.e. applicable to all spheres of life, they must carry information about the levels of human activity in each of the spheres of life, and finally, they must be quantifiable. As such units can be considered the events of the life path of the individual, and the main indicator of productivity with this approach will be the degree of saturation of life with events.

The concept of "event" is widely used in biographical research to analyze "key moments and turning stages in the life of an individual." An event is any change in life - in actions and deeds, thoughts and experiences of a person, in his social environment. Of course, events can be different: some radically change a person's life, others can hardly be noticed in everyday life. The analysis of the significance of events allows taking into account this different scale. The more an event influences the life of a person as a whole, the more 
significant this event is for the person himself. This is evidenced by the data of empirical studies carried out by E.I. Golovakha and A.A. Kronik [8]. Based on this, the productivity of a certain period of life can be measured by the degree of its saturation with significant events, and the productivity of life as a whole is determined by the total saturation of all periods, i.e. number of significant events and life expectancy.

With this approach to the problem in the productivity of life, it is necessary to distinguish between objective significance, which is determined by macro and microsocial consequences, which are the result of certain events in the life of an individual, and the subjective significance of events that occupy key positions in a person's inner world, in his self-assessment of his life. Obviously, the first aspect is directly related to the study of the products of activity, the most important life achievements of a person in the professional, family, socio-political and other spheres of life. The main methodological difficulty here is the construction of an evaluative hierarchy of the social significance of events. The solution to this problem requires a comprehensive study, including axiological, ethical, sociological and socio-psychological aspects, since the objective productivity of life is ultimately measured by the value of social contribution, and all events occurring in a person's life are assessed in terms of their social benefit.

One of the indirect indicators of the objective productivity of life can be a person's selfassessment: how productive a person considers his life. Self-assessment of productivity can be measured using psychological research methods to determine the degree of saturation of life with subjectively significant events. Traditional biographical research provides a qualitative analysis of the subjective significance of events; Diaries, autobiographies, indepth interview data, etc. serve as material for analysis. In this regard, the results obtained are not sufficiently formalized, which allows us to formulate only general conclusions. Objective indicators of the life path do not always coincide with the inner well-being and self-esteem of the individual, this discrepancy is especially acute in the early and late stages of life: in youth, there may be "unrealistic optimism", and at later stages, pessimistic tendencies. In general, most people tend to evaluate their lives in accordance with objectively achieved results of activity, their micro- and macrosocial status. It is no coincidence that the most intense period of life, most people of different ages consider maturity, and the culmination of life is the age range from 30 to 50 years (for men - 35-50, for women - 30-45) [18].

So, there is a definite relationship between objective and subjective indicators of life productivity, but it cannot be interpreted as an unambiguous relationship. It can also be argued that knowledge of the subjective picture of the productivity of life is an essential moment in the study of the problem of human life productivity in its entirety. In this regard, we made an attempt, based on the criteria of the duration and event-richness of life, to apply the method of studying the productivity of life in the self-esteem of an individual and, with its help, to determine the characteristics of the age dynamics of the subjective picture of life productivity, the influence of social and psychological factors affecting the formation of the "picture life".

\section{Conclusion}

Thus, in the psychobiographical approach to measuring the productivity of life, proposed by E.I. Golovakha, there are the following theoretical propositions that underlie the design of the method and the interpretation of the data obtained.

1. Unlike objective productivity, which can be measured only by the saturation with significant events of the past, subjective productivity can be measured in the future as well, according to estimates of future events expected by a person. In this regard, the concept of 
"life expectancy" is used, which reflects a person's ideas about the most likely life expectancy for him.

2. Saturation of life is assessed by a person within the limits of life expectancy for five years - past and future. Each person in the course of the study himself determines the saturation of all five years of life, focusing only on his own memories, plans, expectations.

3. In addition to the saturation of individual periods and life in general, it is possible to measure the relative saturation of the past and the future.

4. As a result of measuring the saturation of all five years of life, a certain graphic image of the life path of an individual can be obtained, which characterizes the dynamics of the subjective picture of life in different age periods.

5. In addition to the richness of life and its individual periods, it is possible to measure the relative richness of the past and the future in the self-consciousness of the individual. The data obtained make it possible to speak about the dominant of a person's past or future, about the degree of subjective realization of his life in terms of productivity.

6. Measuring the expected duration and degree of subjective fulfillment of life opens up the possibility of quantitatively determining the psychological age of a person, one or another value of which we interpret as an indicator of an optimistic, realistic or pessimistic assessment of a person's own life productivity.

In the psycho-biographical approach to the study of professional identity, the concepts of professional vocation, disappointment in the chosen profession, or the experience of vocation are used. For the first time to study the professional vocation or disappointment in the chosen profession, the methods of the psycho-biographical approach were applied by L.G. Peretyatko [19]. Using the methodology "Estimating five-year intervals", she explored alternative life productivity schedules in the chosen teaching profession and in another possible profession, found that students who did not have disagreements in alternative life schedules, after several years of independent work, were convinced that their vocation pedagogy. And those students who had discrepancies in alternative schedules (low productivity in the field of the chosen profession of a teacher), in the majority, chose another profession. Thus, we can say that the psycho-biographical approach at an early stage can reveal how much a person sees himself in the chosen profession, in modern terms, how much a student has a professional identity with the chosen profession [20].

R. A. Akhmerov and N. G. Khakimova showed that with the help of alternative life schedules - "Assessment of five years of life in the field of pedagogy and in another possible profession" it is possible to study professional identity in the psycho-biographical aspect. It is this approach that makes it possible to establish the relationship between the productivity of life in the chosen profession and in another possible profession. If productivity in the chosen profession is higher than in another possible profession, then we can talk about professional identity with the chosen profession.

\section{References}

1. A. V. Brushlinsky, Psychology of the subject, SPb, Aletheia (2003).

2. A. K. Osnitsky, Self-awareness and subjective human activity, Abstracts for the International Scientific and Practical Conference "Individual and group subjects in a changing society", Moscow, 117-118 (1999).

3. T. V. Kudryavtsev, Psychology of vocational training and education, Moscow, Publishing house of the Moscow Power Engineering Institute (1986).

4. E. F. Zeer, Psychology of professional development: textbook for students. higher. Textbook. Moscow, Publishing center "Academy" (2006). 
5. E. A. Klimov, Individual style of activity, Psychology of individual differences, Moscow, CheRo, 140-144 (2002).

6. D. N. Zavalishina, Ways of identification of a person with a profession, Practical thinking (specificity and problems of development). Moscow, IP RAN, 174-198 (2005).

7. R.A. Akhmerov, N.G. Khakimova, Professional identity of students of a pedagogical university in the psychobiographical aspect, In the world of scientific discoveries, 7.1(43), 348-367 (2013).

8. E. I. Golovakha, A. A. Kronik, Personality psychological time. Moscow, Smysl (2008).

9. A. A. Kronik, The picture of life productivity and its dynamics in the selfconsciousness of the individual // Life as creativity: Socio-psychological analysis. Kiev: Naukova dumka, 265-277 (1985).

10. I. V. Antonova, The problem of personal identity, Questions of psychology, 1, 131-143 (1996).

11. T. S. Berezina, Formation of the teacher's professional identity, Pedagogical education and science, 7, 24-27 (2008).

12. O. Ya. Emelyanova, Formation of professional identity in order to adapt an employee to work in his specialty, Vestnik VSU, 2, 153-156 (2005).

13. N. Zhiginas, Stages of the formation of the teacher's professional identity, Hilgher education in Russia, 8, 121 - 122 (2007).

14. L. B. Schneider, Personal, gender and professional identity: theory and methods of diagnosis, Moscow, IPSI Publishing House (2007).

15. L. B. Schneider, Professional identity. Moscow, MOSU (2001).

16. E. I. Golovakha, Life productivity criteria // Life as creativity: Socio-psychological analysis. Kiev: Naukova Dumka, 256-265 (1985).

17. Ch. M. Buhler, F. Massarik, J. Bugental, The Course of Human Life: A Study of Goals in the Humanistic Perspective, Springer Publishing Company (1968).

18. A. A. Kronik, R. A. Akhmerov, Causometry: methods of self-knowledge, diagnostics and psychotherapy in the psychology of the life path, Moscow, Smysl, (2003).

19. L. G. Peretyatko, Professional vocation of the individual (psychological and biographical aspect): author's abstract... Candidate of Psychological Sciences, Moscow (1991).

20. U. S. Rodygina, Psychological features of professional identity of students, Psychological science and education, 4, 39-48 (2007). 